\title{
Toward a transdisciplinary approach of ergonomic design for sustainability
}

\author{
Giuseppe Di Bucchianico a, ${ }^{\mathrm{a}}$, Antonio Marano a and Emilio Rossi ${ }^{\mathrm{a}}$ \\ ${ }^{a}$ Ergonomics and Design for Sustainability Research Unit, IDEA Department, University of Chieti-Pescara, Viale \\ Pindaro, 42, 65127 Pescara, Italy
}

\begin{abstract}
Starting from the results of a theoretical and methodological study on Ergonomic design for sustainability previously developed from the authors, this paper shows the early results of a study that tries to apply them to actual operational and conceptual apparatuses of Ergonomics. In particular, the research aims to verify the possibility for Ergonomics to initiate an update of its current theoretical and procedural tools, towards new design solutions of "sustainable well-being", trying to look for new declinations of its several fields of application. The paper identifies new paradigms and definitions for one of the central themes of ergonomic design, as well as one among the most established and investigated: the usability of products and services.
\end{abstract}

Keywords: Ergonomic design for sustainability, Transdisciplinary approach, Social effectiveness, Relative efficiency, Extended satisfaction

\section{Introduction}

In last decades, Ergonomics has gradually extended its field of application respect to the changes occurred in the claim of health and well-being expressed by people, to improve conditions of life, from workplaces to all daily activities.

"Classical" Ergonomics can be considered essentially as "multidisciplinary" in its contents, availing itself of contribution by several disciplines, and as "interdisciplinary" in the approach to project through mutual exchange of approaches, methods and tools. This is a constructive and coordinated "confrontation" between different disciplines like Psychology, Physiology, Occupational Health, Sociology, Engineering, Architecture, and other ones that, at different levels, offer their own contribution to Ergonomic Design. This approach to project doesn't appear, however, to be able to respond in a sufficiently organic and coordinated way to complexity and novelty of the questions posed by Sustainability. Ergonomics would need to act in a "transversal" way, or better, in a "transdisciplinary" way respect to width of issues related to Sustainability.
Is necessary, indeed, to stake current singular "disciplinary identities" based on a consolidated theoretical and methodological apparatus, in order to identify new "ideas" of well-being. This is possible starting from a critical comparison between some Strategies of Ergonomic Design for Sustainability in which the actual theoretical and instrumental apparatus of Ergonomic Design are no longer usable without an evolution from a "sustainable" viewpoint.

\section{Objectives}

Referring to this problematic scenario, this paper shows the early results of a research conducted by the "Ergonomics and Design for Sustainability" Research Unit of the University of Chieti-Pescara in Italy. The study intends pursuing the previous research, whose results are presented in the paper "Strategies and Arguments of Ergonomic design for sustainability" and in short authors identify some possible "Arguments" or research paths of Ergonomics for Sustainability. Starting from a comparison with specific "Arguments" related to each strategy, the goal of the research was verify the possibility for

\footnotetext{
*Corresponding author. E-mail: pepetto@unich.it.
} 
Ergonomics, to start an updating of actual theoretical-procedural instruments available. This mainly toward adequate conceptual and operative apparatus to the design research of new solutions of "sustainable well-being", with new possible declinations of its different applicative sectors.

In particular, the analysis aims were:

- Evaluate the inadequacy grade of current Ergonomic Design interdisciplinary and disciplinary apparatus of disciplines related to main specialization fields of Ergonomics respect to the questions posed by Sustainability;

- Evaluate whether and how, existing theoretical, methodological and instrumental apparatus of Ergonomic Design can be transformed.

\section{Method}

The research was conducted following a logical path divided in four different phases here described:

\subsection{Individuation of current equipments of Ergonomics}

The first phase of the path was the definition of a scientific background through the individuation of applicative and disciplinary fields of Ergonomic Design. The Ergonomics definition purposed by IEA (International Ergonomics Association) ${ }^{1}$, in fact, identifies its main domains in three "sectors of specialization", or rather, Physical Ergonomics, Cognitive Ergonomics and Organizational Ergonomics. To them, indeed, it is possible to bring all variety of specialist contributions to ergonomic research, both theoretical than applicative. To this three research fields, IEA added another one, strictly referred to Ergonomic Design. It is possible to state, as is underlined by IEA ${ }^{2}$ that, "Human-centered Design", is the activity about which is linked the entire groups of multidisciplinary notions contained in the first three disciplinary fields. The fourth one, thus, became "User-Centered Design" (UCD).

Then, starting from a structure composed by four "disciplinary domains", it has proceeded to the individuation and sistematization of themes and specific aims of ergonomic actions. Thus, it has been

\footnotetext{
1 "What is ergonomics", IEA Council, 2000.

2 In the homepage of IEA official website (http://www.iea.cc) is directly highlighted in the titolation the strict relation between "Ergonomics" and "Human-Centered Design".
}

achieved to a sufficiently extensive collection of arguments, definitions and basic notions, to which, therefore, it has been associated some main methods and tecniques setting out from each discipline for pursuing these objectives.

\subsection{Construction of a testing model}

In order to verify the compatibility of current ergonomics apparatus respect to arguments introduced from Ergonomic design for sustainability, it has been necessary define an interpretative filter composed by "Arguments of Sustainable Ergonomics" that in the previous research are combined to the following five Strategies of Ergonomics for Sustainability ${ }^{3}$ :

- the optimization of the ergonomic life of products, services and workplaces;

- the facilitation of sharing and socializing modalities of products, services, work activities and management;

- the choice of intelligence systems for learning and developing technical skills and creative capabilities;

- the valorization of contemplative time in the aimed actions;

- the cultural, psychological and economicalproductive regeneration of everyday life contexts.

\subsection{Verification and comparison with Arguments of Ergonomics for Sustainability}

The central research phase regards the definition of a procedural model of review, in prospect to a transition toward Sustainability, of notions, principles, aims, methods and techniques that "Traditional Ergonomics" had done in last decades. This was done, through a review process with "Arguments" gonomics for Sustainability.

An early test of this verification model has been conducted onto specific theme of "User-Centered Design": the usability of products and services. It is, in fact, one of the main themes of Ergonomic Design and, therefore, is one of those most investigated and discussed by discipline itself. The idea indeed is that,

\footnotetext{
3 They are "Strategies" and relative "Arguments" that authors (A. Marano, G. Di Bucchianico and E. Rossi) present in the same 18th World Congress on Ergonomics (IEA 2012) with the paper titled: "Strategies and Arguments of Ergonomic Design for Sustainability".

4 Ibidem.
} 
this process of verification, can be later repeated and extended to other ergonomic sectors.

In particular, referring to the usability theme, its main basic notions are submitted to verify (usability, effectiveness, efficiency, and satisfaction ${ }^{5}$ ), with a particular attention to some among the most common and typical aims concerning, for example, of ergonomic assessment, that generally they can be submitted to "objective" evaluations ("execution time of tasks" and "error frequency").

A direct comparison between two groups of elements ("Arguments and Aims of Usability" "Arguments and Aims of Ergonomics for Sustainability") has allowed to point out some inedited and possible relations between them.

In particular, the comparison was done in the following manner:

$$
\mathrm{TU}+\left(\mathrm{SA}_{1}+\mathrm{SA}_{2}+\ldots+\mathrm{SA}_{\mathrm{n}}\right)=\mathrm{U} \cdot \mathrm{S}
$$

where:

- Traditional Usability (TU) is defined as: "...effectiveness, efficiency, and satisfaction in which specific users achieve specific goals in a specified context of use".

- Sustainable Arguments (SA) is divided in two different elements: Creativity $\left(\mathrm{SA}_{1}\right)$ is the individuation of inedited strategies of use; Awareness $\left(\mathrm{SA}_{2}\right)$ is the evolution of decisional processes, from development to skills (how) to awareness of goals (why).

- Usability for Sustainability $(\mathrm{U} \cdot \mathrm{S})$, finally, is defined as: "...effectiveness, efficiency, satisfaction, creativity and awareness in which specific users achieve specific goals in a specified context of use".

In this case, therefore, it has been only implemented the traditional definition of "Usability" with new aspects, expressly derived it from some "Arguments" identified in the previous research ${ }^{6}$, that it should be necessary to submit to "evaluation" in the case of we want to evaluate usability from a typical of sustainable development point of view: users creativity and their complete and active aims awareness to achieve through use (or better, is should be used the term "experience") of analyzed products.

\footnotetext{
${ }^{5}$ The definition is taken from ISO CD 9241-11 applied on VDTs.

${ }^{6}$ It is the research mentioned in the footnote $\mathrm{n}^{\circ} 3$.
}

\subsection{Interpretation and systematization of the results}

The interpretation and systematization of results obtained after the verification and comparison phase with Arguments of Ergonomics for Sustainability, therefore, has allowed to propose an early revision of traditional notions and definitions before tested.

\section{Results}

In case of analyzed notions referred to usability, we have achieved the results reported into the following Table (see Table 1) that underlines conceptual differences between so-called "Traditional Usability" and new "Usability for Sustainability".

New paradigms sets from "sustainable well-being", so, complete, integrate and sometimes modify traditional evaluation elements refer to basic notions of effectiveness, efficiency and satisfaction expressed in the traditional meaning of usability.

In particular, a renovated effectiveness refers also to the "social" dimension of its aims, should be look also toward the possibility of "sharing" with other people, results achieved and to the capacity of "socializing" through the product use; efficiency could "relativizing itself" admitting (and sometimes also allowing it) the possibility to fail ("errorfriendly" products), or considering the opportunity to admit "slow" execution times, in case, they allow reflection and learning (introducing, thus, a new idea of "slow usability"); satisfaction derived from use of product, finally, should "extend itself" to consider values of gratification, of fulfillment, and appreciation of task, also to a dimension not closely as individual one.

It is clear now that this change of the point of view related to usability can modify, radically too, the entire body of notions and "traditional" procedures that are associated them. As is shown before, for example, several criteria of evaluation and measurement decay or they are not adequate and, consequently, it appears an immediate and necessary critical review, both on the conceptual level than on the applicative one, of all groups of methodologies, techniques and survey tools developed, during last decades, from scientific community of Ergonomics. 
Table 1

The evolution of usability paradigms from "Traditional Usability" to "Usability for Sustainability"

\begin{tabular}{|c|c|}
\hline TRADITIONAL USABILITY & USABILITY FOR SUSTAINABILITY \\
\hline $\begin{array}{l}\text { Usability: "...effectiveness, efficiency, and satisfaction in which } \\
\text { specific users achieve specific goals in a specified context of use" }\end{array}$ & $\begin{array}{l}\text { Usability: “...effectiveness, efficiency, satisfaction, creativity } \\
\text { and awareness in which specific users achieve specific goals in a } \\
\text { specified context of use" }\end{array}$ \\
\hline $\begin{array}{l}\text { Effectiveness: accuracy and completeness with which } \\
\text { users achieve the overall goals set by the system }\end{array}$ & $\begin{array}{l}\text { "Extended" Effectiveness: it is also reported to the aims } \\
\text { of: } \\
\text { - Socialization } \\
\text { - Sharing }\end{array}$ \\
\hline $\begin{array}{l}\text { Efficiency: accuracy, completeness obtained in relation to } \\
\text { spent resources (physical effort, metal effort, time, costs) }\end{array}$ & $\begin{array}{l}\text { "Relative" Efficiency: meanings introduced are: } \\
\text { - Relative error: "educative" error (error-friendly) } \\
\text { - Relative time: reflection and learning ("slow" usabil- } \\
\text { ity) }\end{array}$ \\
\hline $\begin{array}{l}\text { Satisfaction: comfort and acceptability in the system use, } \\
\text { subjective user reactions that use the system itself }\end{array}$ & $\begin{array}{l}\text { "Extended" Satisfaction: well-being referred also to: } \\
\text { - Gratification and fulfillment of task } \\
\text { - Appreciation of the value of things }\end{array}$ \\
\hline- & Creativity: individuation of inedited strategies of use \\
\hline- & $\begin{array}{l}\text { Awareness: evolution of decisional processes, from devel- } \\
\text { opment to skills (how) to awareness of goals (why) }\end{array}$ \\
\hline
\end{tabular}

\section{Conclusions}

The research has shown how it is possible to adjust notions, definitions and aims related to traditional issues of Ergonomic Design, this for respond to new needs expressed by sustainable development of contemporary society.

Although in the presence of partial results, indeed, is possible to state that, if the same process of comparison between "Arguments of Ergonomics for Sustainability" and "Notions and Aims of Ergonomic intervention" was conducted on all ergonomic sectors, it might be obtained, with a good chance, a general revision of entire system of notions, principles, aims, methods and techniques that ergonomic disciple has developed during last century.

Considering indeed the systemic complexity of questions that sustainable development sets and considering the necessity of a holistic approach to their situation, we can conclude that current "interdisciplinarity" or "multidisciplinarity" of ergonomic knowledge doesn't be able to manage the process of transformation toward Sustainability, instead, it is necessary to refer to that we can define "transdisciplinarity" of competence. It appears in fact necessary that numerous disciplines related to Ergonomics are "transversely" compared actually for starting an evolution process of Ergonomics for Sustainability. In this way it will be possible reclaim the value of ho- mogenous study of individual ${ }^{7}$ needs also in its aspects, apparently more intangible, of relation with "extended scenario" characterizing a contemporary society oriented to Sustainability.

\section{Credits}

In this paper is shown the result of a common discussion and elaboration work, but the writing of the various paragraphs can be attributed to: Giuseppe Di Bucchianico (4. Results and 5. Conclusions), Antonio Marano (2. Objectives and 3. Methods) and Emilio Rossi (Abstract and 1. introduction).

\footnotetext{
${ }^{7}$ Ethimological meaning of "individual", from lati "individuus" make it, in fact, "invisible".
} 